http://dx.doi.org/20073496.1320

Reseña

\title{
Anaya-Merchant, L. (2020). Luis Montes de Oca (1894-1958): el renovador, el hacendista, el banquero y la familia revolucionaria. México: Universidad Autónoma del Estado de Morelos.
}

Ana Luisa Pérez-Sosa $1, *$

\footnotetext{
${ }^{1}$ Instituto de Investigaciones Dr. José María Luis Mora

* Correspondencia: aperez@institutomora.edu.mx
}

En los intereses historiográficos, particularmente la revaloración del individuo como sujeto histórico, los retos y los cambios han propiciado un nuevo aprecio de la biografía como género histórico. Las biografías contribuyen a comprender la realidad compleja del biografiado, y evitan caer en reduccionismos que suelen condenar a un personaje o evento. Asimismo, permiten comprender las formas en que los individuos son parte de su contexto, a la vez que hacen frente a las distintas estructuras de sus épocas y permiten explorar determinadas tensiones y contradicciones aparentes de una persona. Además, desde la óptica de la persona estudiada, se pueden reconocer distintas condiciones en los procesos históricos. No obstante, la biografía suele ser un género complejo por la multiplicidad de fuentes a las que se recurre con la intención de lograr destacar los distintos roles, percepciones y contextos del biografiado.

Luis Anaya-Merchant, con su obra Luis Montes de Oca (1894-1958): el renovador, el hacendista, el banquero y la familia revolucionaria, propone un "estudio biográfico plausiblemente integrado de la trayectoria” de Luis Montes de Oca, la intención es constituir una percepción más ecuánime, además de esbozar tesis divergentes a las que hoy predominan sobre su imagen. El autor parte de la premisa de que Montes de Oca fue uno de los hombres que la Revolución Mexicana encumbró, aunque su participación en la misma y en el periodo posrevolucionario, así como su legado, no están bien definidas. Anaya-Merchant analiza distintas fuentes que incluyen el archivo personal de Luis Montes de Oca, permitiéndole a este tener voz ante algunas percepciones y versiones de su vida, contrastándolas con las de otros testigos. Además, da cuenta de aspectos privados como sus 
gustos, forma de vida, ingresos, así como archivos públicos que refieren a su trayectoria política y empresarial. La estructura de la biografía sigue un orden cronológico y está dividida en siete secciones, como el propio autor lo indica.

En la primera sección del libro Anaya-Merchant detalla la formación del Montes de Oca. Permite comprender un poco más sus orígenes, las motivaciones sobre sus intereses educativos y la forma en que tejió sus primeras relaciones de amistad. La información que se tiene sobre sus primeros años de vida y sobre su familia directa es muy fragmentada, resultado del anonimato que proporciona la Ciudad de México cuando no se cuenta con grandes recursos económicos. Montes de Oca es descrito como un personaje muy comprometido con su aprendizaje e interesado en actividades culturales, quizá influido por su frágil salud. Ingresó a la Escuela Superior de Comercio y Administración y se vinculó a la Asociación de Contadores Públicos Titulados (ACPT), fundada por Fernando Díaz Barroso e integrada por un grupo de jóvenes poco favorecidos socialmente. Su primer empleo profesional fue en la Dirección General de Catastro, donde experimentó las prácticas burocráticas porfiristas. Asimismo, se sumó a la agitación política en 1913 luego del asesinato de Francisco I. Madero.

La segunda sección del libro refiere a la participación de Montes de Oca en la revolución mexicana y a sus experiencias consulares entre 1913 y 1925 . Aquí se trazan algunas gestiones del biografiado que permiten vislumbrar su participación en la revolución y su desarrollo político. En el texto se destacan cuatro puntos imprescindibles: 1) sus labores periodísticas y propagandistas llevadas a cabo contra el régimen de Victoriano Huerta en El Renovador, pues marcaron el inicio de su actividad política y le permitieron establecer vínculos con operadores políticos como Francisco S. Elías y Alfonso y Roberto V. Pesquería; 2) su vinculación con el grupo Elías y Pesquería a quienes apoyó en Sonora y en la zona fronteriza, donde puso en práctica su dominio del inglés y principios de contabilidad; 3) su colaboración con Ignacio Enríquez, militar chihuahuense vinculado a Obregón, y 4) su desempeño como cónsul en el Paso, Texas, y en ciudades de Europa como Hamburgo y Paris, resultado de sus relaciones y labores, dichas estancias reforzaron sus rasgos cosmopolitas. De este último punto sobresale su labor como cónsul en el Paso, donde desempeñó actividades comerciales, diplomáticas y de espionaje, lo que le hizo a mantenerse en constante movimiento entre el Paso y Juárez, donde consolidó amistades que le dieron el título de chihuahuense honorario.

La tercera sección del libro versa sobre las gestiones de Montes de Oca como contralor entre 1925 y 1927. Se delinean ciertas condiciones que permiten comprender las razones por las que el biografiado inició su trayectoria como "figura con relieve en la nueva casta político-administrativa de la posrevolución”. Puntualmente ayuda a comprender el rol que jugó en la administración callista y sus primeras preocupaciones como funcionario. Se destacan las siguientes aseveraciones evocadas en el texto: Montes de Oca fue designado contralor porque era considerado un funcionario "casi apolítico", "mesurado," recomendado por Arturo M. Elías y "enteramente dependiente de su camarilla”. Montes de Oca reorganizó la Contralaría e hizo de ella "un ministerio paralelo al de Hacienda con pocos recursos", con el apoyo del Instituto de Contadores Públicos Titulados de México (ICPTM), así, siempre se "reputaría como contador público titulado". Montes de Oca procuró no sobrepasar los límites de la política de regulación emprendida por la administración callista, pues a pesar del discurso de reorganización, los favores políticos y excepciones prevalecían entre la familia revolucionaria. 
En su calidad de contralor reconoció la necesidad de cuadros competentes, promovió la capacitación y la recuperación de información veraz para el funcionamiento de la administración. En ese tenor, el autor subraya que se ha olvidado el interés que Montes de Oca mostró por impulsar la educación administrativa, sobre todo en su aspecto moral. El autor puntualiza que las acciones llevadas a cabo por el biografiado como contralor distan de que haya sido "fanático del laissez faire".

Ya en cuarta sección del libro se refiere a la administración de Montes de Oca como ministro de Hacienda (1927-1932), cargo de mayor responsabilidad pública que alcanzó. El autor puntualiza que exploró este proceso porque la historiografía no ha puesto atención a dicho nombramiento, y ha legado "imágenes controvertibles" de las causas que impactaron el desempeño de la "gestión montesdioquista” y que motivaron la renuncia de este. En el texto se señala que la designación de Montes de Oca como secretario de Hacienda fue resultado de un "reacomodo del tablero". Calles requería de funcionarios más leales, competentes y políticamente débiles en puestos clave, caso contrario a Montes de Oca, quien había demostrado su eficacia y "discreción”. Se señala que este fue conciliador con los distintos actores políticos y cercano a sus amigos, resultado de su carácter y experiencia con el grupo sonorense, aunque con cautela restringió "las corruptelas de hombres importantes de la familia revolucionaria”, lo que le generó “desavenencias". En tanto, con el fin de alcanzar soluciones siguió una línea que pretendía "sensibilizar a los sectores económicos y crear convergencias".

Así, a Montes de Oca se le reconoce como un hacendista que impulsó distintos proyectos, y le preocupaban en gran medida la disposición de crédito y la reforma agraria. Le interesaba impulsar nuevas actividades como el turismo a las distintas regiones del país. Aunque no logró buenos resultados en lo general, respecto a ello se apunta que se deben poner en perspectiva la naturaleza de las problemáticas y el contexto que enfrentaba. También en esta sección, se analiza con detenimiento la reforma monetaria de 1931, en relación con su fracaso se enfatiza la falta de apoyo de la banca privada y del Banco de México. Finalmente puntualiza que la salida de Montes de Oca de la secretaria de Hacienda en 1932 no puede entenderse sólo por la crisis económica y los resultados de la ley monetaria, sino que fue parte de la ardua disputa por el poder en la que se ideó la destitución de Pascual Ortiz Rubio, quién era cercano al biografiado.

La quinta sección del libro refiere a los años de retiro de la vida pública de Montes de Oca, entre 1932 y 1935 . Permite ver los múltiples intereses de este con mayor detenimiento, las relaciones de amistad que tenía con distintos personajes nacionales e internacionales, sus posibles influencias intelectuales y las razones de ello. En el texto se especifica que la obra de Montes de Oca en hacienda prácticamente fue desmantelada por Alberto J. Pani, lo que afectó a sus cercanos. Además, señala que, si bien compartía con muchos de su generación el anhelo de reconstruir el país, su característica principal era su necesidad de orden, ya que él era un planificador por excelencia y se reconocía por ser un personaje pacifista, Anaya-Merchant se cuestiona si influyeron sus lecturas sobre Gandhi. Montes de Oca se mantuvo lejos de "los chismes" de la esfera política, sabía que lo vigilaban y que no contaba su favor. La mayor parte del tiempo lo dedicó a asuntos privados y vida social, como el cuidado de sus jardines y a la música, que era su mayor pasión. Sus dos proyectos empresariales más grandes fueron la Compañía Editora Mercurio, de la que obtuvo pocas ganancias, y la Compañía Difusora Continental, que fracasó. Aunque por su propio carácter se interesó y buscó formas de influir en la reorganización ferrocarrilera, la tala clandestina y el desordenado crecimiento urbano. También se mantuvo al tanto de lo que ocurría en el mundo, 
particularmente en Europa. Las posibilidades de conflictos le preocupaban, conocía los efectos de las guerras. Ello le llevo a interesarse por las nuevas ideas liberales y las que reflexionaban en torno a la democracia.

La sexta sección, penúltima del libro, aborda sus gestiones como director del Banco de México entre 1935 y 1940 . El interés del autor es mostrar los límites del biografiado como banquero central al colaborar en la política económica cardenista, porque quizás desde esos límites se entiendan mejor algunas posturas de Montes de Oca hacia Cárdenas y su régimen. Se indica que Montes de Oca regresó a la política gracias a la ruptura de Cárdenas con el callismo, pero con esta misma administración dio por terminada su carrera como funcionario público, rompió con la conflictiva familia revolucionaria en 1940 ya que no estaba de acuerdo con el grupo y las políticas de Manuel Ávila Camacho. Se enfatiza que Montes de Oca y Cárdenas tenían experiencias y anhelos comunes, que los caracteriza como hombres pragmáticos y mucho menos idealizados de lo que se afirma. Además se profundiza en la tensa relación entre Montes de Oca, Lázaro Cárdenas y Eduardo Suárez, entonces secretario de hacienda, por el manejo de cuentas, la falta de planificación y la omisión de ciertas reglas e información, así como la incertidumbre que ello propiciaba. El biografiado cuestionaba el beneficio social que generaban las políticas implementadas. Respecto a los intereses intelectuales y negocios de Montes de Oca, se destaca que fundó la Compañía Editorial: periódicos, libros y revistas. S.A., tradujo el libro The good society de Walter Lippman (que por su alto costo debió tener poco impacto) y se interesó por traer a intelectuales para discutir las nuevas ideas que rondaban por el mundo. Consideraba que era importante estar informados e intercambiar ideas, particularmente en la academia, lo cuál había sido uno de sus propósitos desde que él se desempeñaba como cónsul.

Finalmente, la última sección da cuenta de la actividad empresarial y cultural de Montes de Oca hasta su muerte, en 1958. En esta última etapa, a la par de sus éxitos empresariales, su salud disminuía. El autor subraya que se debe considerar con cautela la afirmación de que Montes de Oca pudo emplear información privilegiada, y argumenta que en dicha etapa se presentaron cambios constantes en la reglamentación bancaria, lo que es cierto, pero la experiencia y las relaciones que obtuvo al haberse desempeñado en cargos de alto nivel no deben perderse de vista. De entre sus negocios destaca su actividad bancaria, particularmente en la cadena del Banco Internacional S. A. (Bital), proyecto en el que trabajó arduamente. Resulta muy sugerente lo señalado en este periodo por las múltiples empresas en las que tuvo presencia, aunque desgraciadamente la atención que recibe es menor, quizá por lo complejo que resultaría desarrollar este tema en la obra o simplemente porqueno era un propósito del autor.

Para Anaya-Merchant, Luis Montes de Oca fue un “personaje multifacético al que le interesaba propiciar el bienestar social y entendía que este era un objetivo amplio que implicaba muchas áreas y muchas más acciones concretas"; fue dedicado y honesto, imaginó otros futuros posibles, además tuvo más éxitos como empresario que como político, pues muchos de sus proyectos políticos fueron inacabados o son muy cuestionables. Aún a pesar de esto, Montes de Oca fue "otro de los constructores del México moderno en una de sus etapas más inciertas”. El autor precisa que no se debe asumir que el estado actual de las instituciones en las que el biografiado influyó son su responsabilidad, como es el caso del Instituto Tecnológico Autónomo de México (ITAM), ya que las ideologías neoliberales con las que se le asocia a dicha institución permearon en ella después de la muerte de Montes de Oca. 
Luis Montes de Oca (1894-1958): el renovador, el hacendista, el banquero y la familia revolucionaria es en suma interesante pues no solo da cuenta de las distintas facetas, estrategias y los entretelones en los que se movilizó Luis Montes de Oca, sino que permite reflexionar sobre la configuración, la caracterización y los conflictos de la familia revolucionaria, así como sobre la conformación del Estado posrevolucionario. Además brinda pistas sobre el desarrollo bancario en México, cuestiona una serie de asuntos referentes a la imagen que se tiene sobre Montes de Oca e incluso de algunos otros personajes de su tiempo e invita a poner mayor atención sobre temáticas que a consideración del autor debían de ser estudiadas. 